\title{
Letter by Teerlink et al Regarding Article, "The Myosin Activator Omecamtiv Mecarbil Increases Myocardial Oxygen Consumption and Impairs Cardiac Efficiency Mediated by Resting Myosin ATPase Activity"
}

\author{
John R. Teerlink, MD, FAHA ${ }^{1}$, Fady I. Malik, MD, PhD $^{2}$, and David A. Kass, MD, FAHA ${ }^{3}$ \\ ${ }^{1}$ San Francisco Veterans Affairs Medical Center and University of California San Francisco, San \\ Francisco, CA \\ ${ }^{2}$ Cytokinetics, Inc., South San Francisco, CA \\ ${ }^{3}$ The Johns Hopkins University Medical Institutions, Baltimore, MD
}

\begin{abstract}
We reviewed the paper, "The Myosin Activator Omecamtiv Mecarbil Increases Myocardial Oxygen Consumption and Impairs Cardiac Efficiency Mediated by Resting Myosin ATPase Activity,"1 with interest because its conclusions differ from our work published in this same journal $^{2}$ and elsewhere. ${ }^{3} \mathrm{We}$ commend the authors for pursuing an important question related to an investigational drug being studied in patients with systolic heart failure. However, we believe deficiencies in their experimental approach undermine their conclusions.
\end{abstract}

First, despite the title of the manuscript, there was no statistically significant difference in directly measured myocardial oxygen consumption preceding and following omecamtiv mecarbil administration (Table $2^{1}$ ). In contrast to the prior work in a conscious dog model of heart failure ${ }^{2}$ the authors studied animals under acute anesthesia in which $30 \%$ of the animals had to be excluded due to hemodynamic collapse. A critical placebo control group to determine effects of change in hemodynamic status over time was not performed. Without such a control, one cannot disentangle the effect of time from the effect of the drug.

Second, to assess the pressure-volume-area oxygen consumption relationship, the investigators reduced preload in a graded manner; in doing so the investigators appeared to reduce cardiac stroke work to near zero. It is difficult to understand how this was achieved,

\footnotetext{
Correspondence to: John R. Teerlink, MD, FACC, FAHA, FESC, FRCP(UK), Professor of Medicine, University of California San Francisco (UCSF), Director, Heart Failure Program, SFVAMC, Director, Clinical Echocardiography, SFVAMC, San Francisco Veterans Affairs Medical Center, Cardiology, 111C; Building 203, Room 2A-49, 4150 Clement Street, San Francisco, CA 94121-1545 USA, Phone: +1 (415) 221-4810, x4160, Fax: +1 (415) 750-6950.

John R. Teerlink, MD San Francisco Veterans Affairs Medical Center and University of California San Francisco, San Francisco, CA, USA

Fady I. Malik, MD, PhD Cytokinetics, Inc., South Francisco, USA

David A. Kass, MD The Johns Hopkins University Medical Institutions, Baltimore, MD, USA

Disclosures

JRT has received research grants and consulting fees from Abbott, Actelion, Amgen, Bayer, Cardioxyl, Cytokinetics, Novartis, Theravance, and Trevena. FIM is an employee and stockholder of Cytokinetics, Inc. DAK has received research grants and consulting fees from Amgen and Cytokinetics.
} 
and why this maneuver, performed twice during the experimental protocol, would not itself alter energetics. It would seem quite difficult to sustain such marked preload (and thus stroke work) reduction for any time at all without substantial sympathetic activation or inducing ischemic damage. Even prior to performance of these maneuvers in the healthy animals, increases in both heart rate and $\mathrm{dP} / \mathrm{dt}$ occurred in the first 20 minutes before omecamtiv mecarbil administration. In fact, $\mathrm{dP} / \mathrm{dt}$ continued to rise during drug administration, something not observed in prior studies. The authors attributed this to the drug, but without a placebo control, this conclusion cannot be made.

Third, the conclusion that omecamtiv mecarbil increases resting myosin ATPase is contradictory to the finding that omecamtiv mecarbil inhibits the non-actin dependent myosin ATPase in purified systems. ${ }^{3,4}$ The authors instead use whole hearts subjected to cardioplegia in which the activation state of the sarcomere is not well defined and calcium concentrations in the myocyte are unstable. ${ }^{5}$ Even modest changes in basal calcium will result in sarcomere activation by omecamtiv mecarbil rendering measurements of a basal state inaccurate and uninterpretable.

Finally, the authors employed a dose of omecamtiv mecarbil that is 3-fold higher than the highest doses studied in humans. Assuming infusions were administered correctly (dose reported is in $\mathrm{mg} / \mathrm{kg} / \mathrm{min}$ in abstract and $\mathrm{mg} / \mathrm{kg} / \mathrm{h}$ in methods), the selected dose $(0.92$ $\mathrm{mg} / \mathrm{kg} / 20 \mathrm{~min})$ was nearly 3 -fold higher than that employed in conscious dogs $(0.33$ $\mathrm{mg} / \mathrm{kg} / 20 \mathrm{~min})^{2}$ and the maximum dose-rate studied in humans $(\sim 0.33 \mathrm{mg} / \mathrm{kg} / 20 \mathrm{~min}){ }^{6}$ Currently, considerably lower doses are being pursued in the ongoing clinical development program. Since plasma concentrations of omecamtiv mecarbil were not measured, the relevance of the dose studied to the doses now being employed in humans cannot be assessed.

Based on these concerns, we believe this study, with its design limitations and absence of necessary controls, could not adequately address the important hypotheses proposed by the authors and thus does not support their main conclusions.

\section{References}

1. Bakkehaug JP, Kildal AB, Engstad ET, Boardman N, Næsheim T, Rønning L, Aasum E, Larsen TS, Myrmel T, How OJ. The Myosin Activator Omecamtiv Mecarbil Increases Myocardial Oxygen Consumption and Impairs Cardiac Efficiency Mediated by Resting Myosin ATPase Activity. Circ Heart Fail. 2015 CIRCHEARTFAILURE.114.002152. [Epub ahead of print].

2. Shen YT, Malik FI, Zhao X, Depre C, Dhar SK, Abarzúa P, Morgans DJ, Vatner SF. Improvement of cardiac function by a cardiac myosin activator in conscious dogs with systolic heart failure. Circ Heart Fail. 2010; 3:522-7. [PubMed: 20498236]

3. Malik FI, Hartman JJ, Elias Ka, Morgan BP, Rodriguez H, Brejc K, Anderson RL, Sueoka SH, Lee KH, Finer JT, Sakowicz R, Baliga R, Cox DR, Garard M, Godinez G, Kawas R, Kraynack E, Lenzi D, Lu PP, Muci A, Niu C, Qian X, Pierce DW, Pokrovskii M, Suehiro I, Sylvester S, Tochimoto T, Valdez C, Wang W, Katori T, Kass DA, Shen YT, Vatner SF, Morgans DJ. Cardiac myosin activation: a potential therapeutic approach for systolic heart failure. Science. 2011; 331:1439-43. [PubMed: 21415352]

4. Liu Y, White HD, Belknap B, Winkelmann DA, Forgacs E. Omecamtiv Mecarbil modulates the kinetic and motile properties of porcine $\beta$-cardiac myosin. Biochemistry. 2015; 54:1963-1975. [PubMed: 25680381] 
5. Brachmanski M, Gebhard MM, Nobiling R. Separation of fluorescence signals from Ca2+ and NADH during cardioplegic arrest and cardiac ischemia. Cell Calcium. 2004; 35:381-91. [PubMed: 15036954]

6. Teerlink JR, Clarke CP, Saikali KG, Lee JH, Chen MM, Escandon RD, Elliott L, Bee R, Habibzadeh MR, Goldman JH, Schiller NB, Malik FI, Wolff AA. Dose-dependent augmentation of cardiac systolic function with the selective cardiac myosin activator, omecamtiv mecarbil: a first-inman study. Lancet. 2011; 378:667-675. [PubMed: 21856480] 